\title{
Do individual differences in need strength moderate the relations between basic psychological need satisfaction and organizational citizenship behavior?
}

\author{
Burkhard Wörtler ${ }^{1}$ (1) - Nico W. Van Yperen ${ }^{1}$ - Dick P. H. Barelds ${ }^{1}$
}

Published online: 27 June 2019

(c) The Author(s) 2019

\begin{abstract}
An important theoretical debate in the literature on psychological needs concerns the potential moderating role of individuals' need strength in the effects of basic psychological need satisfaction. The present study adds to the relatively small literature with inconsistent findings by examining whether the relations between work-related basic psychological need satisfaction (autonomy, competence, and relatedness) and organizational citizenship behavior (i.e., constructive voluntary job performance) are enhanced when employees' work-specific explicit need strength increases. Survey data from two samples of employees in the United States $\left(N=353 ; M_{\text {Age }}=38.13\right)$ and in the Netherlands $\left(N=298 ; M_{\text {Age }}=44.57\right)$ consistently showed that across the need domains, need satisfaction was positively associated with organizational citizenship behavior through work engagement. However, we only found minor evidence for a moderating role of need strength. These findings largely endorse core self-determination theory assertions, as they underscore the relevance of employees' psychological need satisfaction rather than fit between high psychological need satisfaction and high need strength in the workplace.
\end{abstract}

Keywords Psychological needs $\cdot$ Need strength $\cdot$ Organizational citizenship behavior $\cdot$ Work engagement $\cdot$ Selfdetermination theory

\section{Introduction}

In self-determination theory (SDT), the satisfaction of individuals' psychological needs for autonomy, competence, and relatedness has been identified as essential for sustaining optimal psychological functioning and motivation (Deci and Ryan 2000; Ryan and Deci 2000; Vansteenkiste and Ryan 2013). The need for autonomy refers to the desire of individuals to act on their own volition and have choices and psychological freedom. The need for competence refers to the desire of individuals to interact effectively with their environment by attaining valued outcomes and mastering challenges. The need for relatedness (cf., Baumeister and Leary 1995) refers to individuals' desire to connect meaningfully with others. There are at least two reasons why a scientific investigation of these needs is apposite. First, they

Burkhard Wörtler

b.wortler@rug.nl

1 Department of Psychology, University of Groningen, Grote Kruisstraat 2/1, 9712 TS Groningen, The Netherlands are deemed basic or inherent human needs (Deci and Ryan 2000). Thus, they would be applicable to all individuals, regardless of their culture, ethnicity, or subgroupings in general. Second, basic psychological need satisfaction (BPNS) is pertinent for explaining outcomes in a variety of central life domains, such as work (see Van den Broeck et al. 2016), education (e.g., Korthagen and Evelein 2016), and sports (e.g., Hodge et al. 2009).

In the present research, our main aim was to examine whether individual differences in work-specific need strength moderate an indirect relation between work-related BPNS and organizational citizenship behavior (OCB; Organ 1997) through work engagement. OCB is formally defined as "individual behavior that is discretionary, not directly or explicitly recognized by the formal reward system, and in the aggregate promotes the efficient and effective functioning of the organization" (Organ et al. 2006, p. 3). We refer to work-specific autonomy, competence, and relatedness need strength as individual differences in the expressed need for 
autonomy, competence, and relatedness at work, respectively (cf., Katz et al. 2010). ${ }^{1}$

There were four pertinent reasons for conducting the present research. First, an important theoretical debate in the literature on psychological needs is that about the potential moderating role of need strength on the relations between BPNS and outcomes (e.g., Soenens et al. 2015; Van Assche et al. 2018). This debate is sustained owing to inconsistent empirical findings (e.g., Chen et al. 2015; Hofer and Busch 2011; Schüler and Brandstätter 2013; Van Assche et al. 2018). Second, considering an empirically supported claim that the moderating role of need strength may depend on domain-specific outcome variables (Schüler et al. 2013), we sought to strengthen the evidence for this insight by focusing on inherently domain-specific outcome variables of BPNS. Third, although the moderating role of need strength has been supported in some studies, the scope of outcome variables seems to be limited to variables such as flow and psychological well-being (including satisfaction and motivation outcomes); work behavior/performance as an outcome of BPNS (Deci et al. 2017) has not been considered. Finally, the moderating role of work-specific need strength has not received attention in previous research. Investigating individual differences in needs with a domain-specific focus has been encouraged, given that individuals' need strength is likely to vary across domains such as education and work (Flunger et al. 2013). Before we elaborate on the expected moderating role of need strength, we first explain the presumed relations between BPNS and OCB.

\section{The relations between BPNS and OCB}

Employees are compensated for executing the tasks entailed in their job description. However, employees may do more than is required. They may help each other out when necessary, take the time to advise, coach, or mentor each other, or volunteer for extra work assignments (Fox et al. 2012). These behaviors, which are not typically required

\footnotetext{
${ }^{1}$ In the few previous studies that addressed the moderating role of explicit need strength, the operationalization of need strength distinguished need valuation and need desire (e.g., Chen et al. 2015). According to Chen et al. (2015, p. 219), need valuation is "presumably learned from experiences of having the need satisfied and finding it of value", whereas "need desire can be rooted in the frustration of the psychological needs, suggesting that need desire may reflect the wish to overcome a deficit in need satisfaction". In the current research, we adopted the more neutral conceptualization of need strength used by Katz et al. (2010), because we were interested in employees' level or manifestation of needs for autonomy, competence, and relatedness at work. The current conceptualization of need strength was in line with previous research addressing that variable in the work domain (Van Yperen et al. 2014).
}

contractually from employees, are illustrative of OCB. As a class of voluntary work behavior, OCB is a component of the multifaceted criterion of job performance (e.g., Rotundo and Sackett 2002). Empirical research has confirmed that OCB is associated with a variety of individual-level and organizational-level benefits (for meta-analytic findings, see Podsakoff et al. 2009), including overall organizational effectiveness (e.g., Yen and Niehoff 2004).

BPNS may increase the likelihood of employees showing $\mathrm{OCB}$, as "basic psychological needs represent an energetic resource that propels a variety of motivated behaviors" (Vansteenkiste et al. 2010, p. 133). Accordingly, within the basic self-determination theory model relating to the workplace, BPNS is conceptualized as an antecedent of work performance (Deci et al. 2017). Given the empirically supported independent predictive utility of each need for work-related outcomes (Van den Broeck et al. 2016), we surmised the existence of a positive link between the satisfaction of each basic psychological need and OCB (see also Roche and Haar 2013).

An additional objective of the present research was to provide initial evidence that work engagement is an intermediate variable through which work-related BPNS and OCB are related, probably as a function of employees' work-specific need strength. BPNS is an energizing psychological resource (Deci and Ryan 2000; Fernet et al. 2013) that is likely to enhance work engagement (Trépanier et al.2013; Vansteenkiste et al. 2007). Work engagement refers to "a positive, fulfilling, work-related state of mind that is characterized by vigor, dedication, and absorption" (Schaufeli et al. 2002, p. 74). Vigor entails the experience of high levels of mental energy, dedication entails a sense of enthusiasm and the experience of one's work as significant, and absorption refers to complete immersion in the tasks to be accomplished (Bakker et al. 2008).

On-the-job autonomy is a key job resource for facilitating employees' work engagement (Bakker and Demerouti 2008). Thus, employees' sense of behaving according to their will, and of having a choice (i.e., experiencing satisfaction of the need for autonomy), is likely to be positively associated with work engagement. Moreover, work-related satisfaction of the need for competence and work engagement are likely to be related as well, considering that Xanthopoulou et al. (2007) observed a positive correlation between self-efficacy and each of the components of work engagement. Although there are conceptual differences between self-efficacy and the satisfaction of the need for competence, it has been surmised that individuals high in self-efficacy are likely to have a satisfied need for competence and vice versa (Van den Broeck et al. 2010). More suggestive evidence for a positive link between competence satisfaction and work engagement is the positive association between daily attainment of work goals (i.e., work-related competence satisfaction) and 
employees' daily activated pleasurable affect (Harris et al. 2003). Finally, work-related relatedness satisfaction may be positively associated with work engagement. For example, May et al. (2004) found that employees whose relations with their coworkers as well as their supervisors were rewarding and supportive reported higher degrees of psychological engagement (see also Bakker and Demerouti 2008).

Work engagement, in turn, is likely to be positively associated with OCB (Bakker et al. 2012; Christian et al. 2011). In fact, Dalal et al. (2012, p. 314) found employees' engagement to be "the most important cognitive-affective predictor of OCB". For engaged employees, working is a pleasurable and positively significant experience rather than a compulsion (Bakker et al. 2008). Therefore, it is conceivable that high levels of work engagement lead to employees taking on extra tasks that in some way or another relate to-but are not formally part of - their job responsibilities. For example, Salanova and Schaufeli (2008) showed that work engagement is positively associated with proactivity in the workplace. In addition, studies have shown that work engagement is accompanied by a positive mood (e.g., Van Wijhe et al. 2011), which is thought to be a pivotal antecedent to various desirable organizational behaviors (George and Brief 1992; Spector and Fox 2002). Accordingly, for each basic psychological need (autonomy, relatedness, and competence), we predicted that a positive indirect relation exists between work-related need satisfaction and OCB through work engagement (Hypothesis 1).

\section{The moderating role of individual differences in work-specific need strength}

Our primary objective, however, was to show that the predicted indirect relations between work-related BPNS and OCB (as well as the corresponding direct relations) would vary as a function of employees' work-specific explicit autonomy, competence, and relatedness need strength. Psychological needs have traditionally been conceptualized as individual difference variables in theories relating to the work domain (Gagné and Deci 2005). For example, individual differences in the explicit need for autonomy at work were related to employees' perceived effectiveness of timeand location-independent working (Van Yperen et al. 2014) and intrinsic work motivation (Van Yperen et al. 2016). However, whether need strength moderates the relations between work-related BPNS and work-related outcomes has not hitherto been examined.

The reason may be that BPNS is equally beneficial to all individuals from the perspective of SDT (Deci and Ryan 2000). This has been referred to as the "universal hypothesis" (Schüler et al. 2013, p. 482). However, more recently, it has been forwarded that the existence of individual differences as moderators of relations between BPNS and outcomes, and the universal hypothesis are not necessarily mutually exclusive (see Soenens et al. 2015). According to this standpoint, a moderating role of need strength is tenable from a more liberal universalistic consideration of basic psychological needs if need strength merely alters the strength of the association between BPNS and outcomes rather than confines such associations to exist at comparatively higher levels of need strength (Soenens et al. 2015; see also Van Assche et al. 2018).

By contrast, another theory of psychological needs, motive disposition theory (MDT; McClelland 1985), is explicitly concerned with differences in need strength (Sheldon and Schüler 2011). MDT distinguishes implicit motives for achievement, affiliation, and power, which are "conceptualized as early acquired and relatively stable motive dispositions that vary from person to person" (Schüler et al. 2010, p. 1). According to the "matching hypothesis" of MDT (Schüler et al. 2013, p. 482), experiencing need satisfaction is more beneficial for those individuals with a comparatively strong corresponding motive. Important to note is that the matching hypothesis maintains that even individuals low in need strength benefit from need satisfaction (Schüler et al. 2019, 2013). Although the conceptualizations of basic psychological needs and implicit motives differ (Chen et al. 2015; Schüler et al. 2013), the idea of need or motive strength as a moderator variable should be applicable within the framework of both theories (Chen et al. 2015; Van Assche et al. 2018). ${ }^{2}$ However, empirical findings regarding the matching hypothesis are inconsistent.

The results of some studies clearly endorse the postulate of the matching hypothesis (Katz et al. 2010; Schüler and Brandstätter 2013; Schüler et al. 2013, 2010). Katz et al. (2010) found that teachers' support of students' basic psychological needs was positively associated with autonomous motivation for doing homework, yet this relation was stronger for students who were relatively high in domainspecific explicit need strength than for their counterparts who were relatively low in domain-specific explicit need strength. Likewise, Schüler et al. (2010) found that undergraduate students' competence satisfaction in a sports activity was positively related to flow and intrinsic motivation, particularly for participants with a strong implicit achievement motive. However, they did not find evidence for the matching hypothesis when explicit need strength was considered. In terms of the experience of flow in sports, Schüler and Brandstätter (2013), who also relied on implicit motive

\footnotetext{
${ }^{2}$ We use the term "need strength" as an umbrella term for basic psychological need strength (self-determination theory; Deci and Ryan 2000) and implicit motive strength (motive disposition theory; McClelland 1985).
} 
measures, found evidence for the matching hypothesis within the competence and relatedness need domains.

The results of other studies yielded mixed support for the matching hypothesis. For example, Hofer and Busch (2011) found that the implicit achievement motive enhanced the relation between competence satisfaction and job satisfaction in accordance with the assertion of the matching hypothesis. However, the positive relation between relatedness satisfaction and relationship satisfaction was absent for participants low in the implicit affiliation motive. In the educational domain, Flunger et al. (2013) found that domain-specific explicit autonomy, competence, and relatedness need strength, as a composite variable, moderated the positive relation between BPNS and situational interest in school subjects in accordance with the tenet of the matching hypothesis. Flunger et al. (2013) also found a positive effect of students' competence satisfaction on their situational interest in school subjects when the students' domain-specific explicit need for competence was high rather than when it was low. No moderation effect was found when other needs or dependent variables were considered. Schüler et al. (2016) showed that individuals relatively high in implicit autonomy need strength benefitted more from autonomy satisfaction in terms of flow experiences and well-being than did their counterparts low in implicit autonomy need strength. However, the results did not consistently support the positive relations between autonomy satisfaction and outcomes for individuals relatively low in autonomy need strength. Furthermore, they did not find support for a moderating effect of explicit need strength (cf., Schüler et al. 2010). Van Assche et al. (2018) found support for several, but not all, tested interaction effects of autonomy satisfaction and autonomy need strength. For example, in a sample comprising South African young adults, these authors provided evidence that the stronger participants' explicit desire for autonomy, the more they benefited from autonomy satisfaction in terms of well-being; however, they found that the association did not hold for participants very low in autonomy need strength.

Other studies did not provide any support for the matching hypothesis. Relying on samples of students from various countries, Chen et al. (2015) examined the moderating effects of explicit autonomy, competence, and relatedness need valuation (Study 1) and need desire (Study 2) on the relation between the corresponding need satisfaction and well-being. Regardless of their operationalization of need strength, Chen et al. (2015) only found main effects of need satisfaction on well-being. Similarly, Sheldon and Schüler (2011) found that neither implicit nor explicit need strength moderated the relation between university students' need satisfaction and well-being.

In an attempt to reconcile inconsistent findings for the matching hypothesis, Schüler et al. (2013) pointed out that the moderation effect had been supported when domain-specific rather than general outcome variables had been considered. In their own studies, Schüler et al. (2013) replicated this pattern of findings. In line with their predictions, the implicit achievement motive enhanced the effects of competence satisfaction on domain-specific rather than general flow and well-being in the work context (Study 1) and in an academic learning setting (Study 2). The interactive effect on employees' flow experience is particularly interesting to the current research, as flow has conceptual overlap with the absorption element of the work engagement construct (see Schaufeli et al. 2002). Schüler et al.'s (2013) empirically supported assumption that the specificity of the outcome variable matters for finding an interaction effect, is in accordance other findings favoring (e.g., Katz et al. 2010; Schüler and Brandstätter 2013; Schüler et al. 2010) and refuting (Chen et al. 2015; Sheldon and Schüler 2011) the matching hypothesis.

Building on the findings provided by Schüler et al. (2013) and Hofer and Busch (2011), who confirmed the matching hypothesis for work-specific outcome variables, in the present research, we relied on inherently domain-specific outcome variables (i.e., the work-specific variables OCB and work engagement) to test the matching hypothesis. Moreover, we examined employees' work-related psychological need strength. Previous studies concerned with individuals' domain-specific basic psychological need strength found evidence for an interaction effect (Flunger et al. 2013; Katz et al. 2010). Thus, as shown in Fig. 1, we predicted that positive direct relations between work-related satisfaction of each basic psychological need (autonomy, competence, and relatedness) and both OCB and work engagement strengthen as employees' corresponding work-specific need strength increases (Hypothesis 2). Combining Hypotheses 1 and 2, Hypothesis 3 states that positive indirect relations between work-related satisfaction of each basic psychological need and OCB through work engagement strengthen as employees' corresponding work-specific need strength increases. To test these hypotheses, we recruited employees in the United States (Sample 1) and in the Netherlands (Sample 2). The two independent samples are described in the next section.

\section{Method}

\section{Participants and procedure}

Sample 1 Participants in the United States were recruited via Amazon Mechanical Turk (MTurk), a crowdsourcing platform. Use of MTurk for research purposes enables access to a large, stable, and diverse participant pool (Mason and Suri 2012), and provides data that are as reliable as data obtained using traditional methods (Buhrmester et al. 2011). Landers and Behrend (2015), who examined sample sources used in 
Fig. 1 Conceptual research model

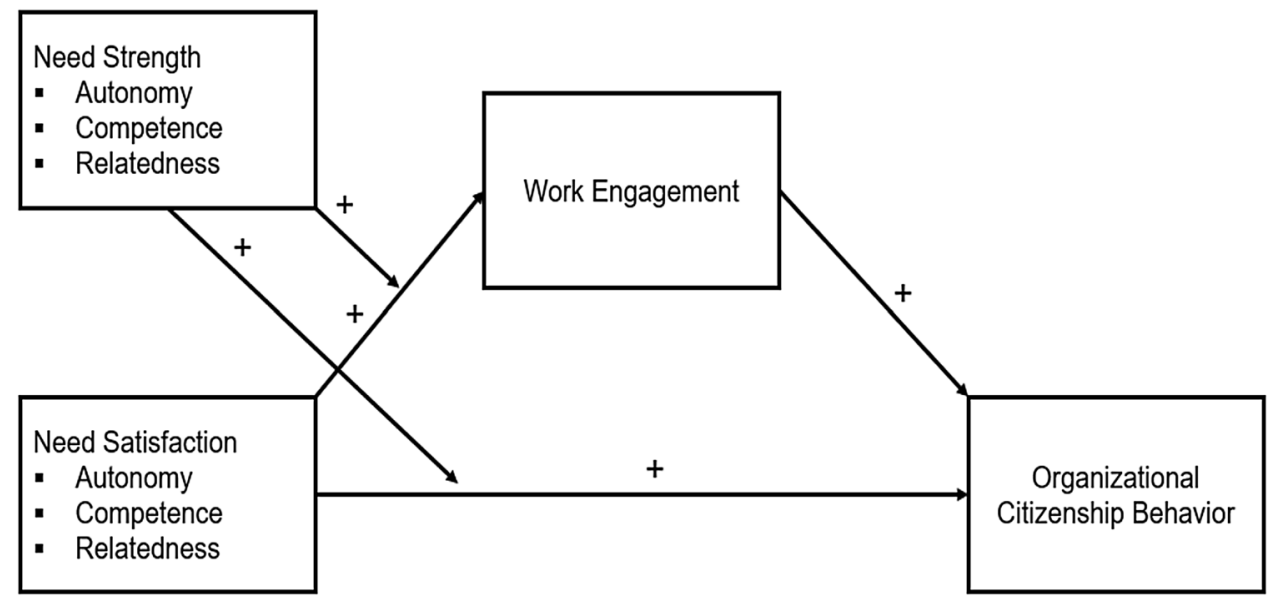

industrial-organizational studies in psychology, concluded that MTurk samples are comparable in quality to more common convenience samples, such as organizational samples. A recent investigation pointed out that there is emerging interest in the use of MTurk samples within the organizational sciences (Keith et al. 2017).

Participants' responses were not considered if they indicated that their data should not be used at the end of the survey, if they completed the survey in less than $10 \mathrm{~min}$, or if they did not complete the survey. In addition, the responses of participants who were not within the age range of 18 and 65 years, who did not work at least $8 \mathrm{~h} /$ week, and who provided an inadequate response to bogus items (Meade and Craig 2012) that were specifically designed to detect careless responses or inattentiveness (Cheung et al. 2017) were excluded.

The analyzed sample, comprising 353 employees (62\% female), was heterogeneous. Participants' ages ranged between 19 and 65 years $(M=38.13, S D=11.75)$, and they worked $8-50 \mathrm{~h} /$ week $(M=37.49, S D=10.26)$. Indications of work hours over $50(n=28)$ were recoded into 50 . In terms of employment status, most participants were permanent employees (85\%). Participants worked in a variety of industries, with the "educational sector" and the "retail trade and catering sector" being predominant (both 14\%). On the MTurk website, the participants were given access to a survey (described below) via a weblink. After completing the survey, they were monetarily compensated for their efforts.

Even though MTurk is a reputable source of respondent samples that has been promoted within the literature (e.g., Buhrmester et al. 2011), we additionally recruited an organizational convenience sample. Employees registered with MTurk tend to have certain demographic characteristics that differ from the general population. In their review of research findings, Paolacci and Chandler concluded that they "tend to be younger (about 30 years old), overeducated, underemployed, less religious, and more liberal than the general population" (2014, p. 185). Furthermore, our intention was to widen the international generalizability of findings and conclusions by including a European sample.

Sample 2 Data were collected from Dutch-speaking employees. Participants were recruited via a Dutch consultancy firm that provided electronic access to our questionnaire (described below) to the employees of various Dutch companies that had business relations with this firm. After participating in an assessment conducted by the consultancy firm, employees were asked to complete our survey on a voluntary basis. The responses of participants who were not between 18 and 67 years of age were discarded. Other than that, we used the same exclusion criteria as we used in the first sample. The analyzed sample comprised 298 employees (50\% female). Again, the sample was heterogeneous: participants' ages ranged from 21 to 67 years $(M=44.57, S D=10.00)$ and they worked between 10 and $50 \mathrm{~h}$ per week $(M=37.50, S D=8.01)$. Indications of work hours exceeding $50(n=16)$ were recoded into 50 . In terms of participants' employment status, most (81\%) were permanent employees. The participants worked in various industries, with the "health care and social assistance sector" (19\%) and the "financial and business sector" (18\%) being predominant.

\section{Materials}

The measures were part of a more general online self-report survey conducted on occupational well-being and job performance over the past 12 months, which was administered in English (Sample 1) and Dutch (Sample 2). We computed scale scores by averaging item scores after we had recoded reversed items.

Need satisfaction Work-related autonomy, competence, and relatedness satisfaction were measured using the Workrelated Basic Need Satisfaction scale (W-BNS scale; Van 
den Broeck et al. 2010). We provided a response scale ranging from (1) totally disagree to (7) totally agree; participants used this to respond to items relating to the satisfaction of each of the basic needs in the workplace. Examples include "I felt free to do my job the way I thought it could best be done" (autonomy satisfaction; $\alpha=.80$ in Sample 1 and $\alpha=.84$ in Sample 2), "I was good at the things I did in my job" (competence satisfaction; $\alpha=.82$ in Sample 1 and $\alpha=.81$ in Sample 2), and "At work, I felt part of a group" (relatedness satisfaction; $\alpha=.90$ in Sample 1 and $\alpha=.81$ in Sample 2). Higher scores indicated more agreement that a need was satisfied at work in the past 12 months.

Need strength Participants' work-specific explicit needs for autonomy, competence, and relatedness were measured using 12 items, which were developed by Van Yperen et al. (2014). The items were evenly distributed among the three need domains. Participants responded to items on a scale ranging from (1) not at all to (7) to an extremely large extent. Examples of items include "At work I have the need for freedom to do my work in the way that I think is best" (need for autonomy; $\alpha=.88$ in Sample 1 and $\alpha=.89$ in Sample 2 ), "At work I have the need to feel that I can finish difficult tasks successfully" (need for competence; $\alpha=.83$ in Sample 1 and $\alpha=.75$ in Sample 2), and "At work I have the need to feel like I am part of a team or a group" (need for relatedness; $\alpha=.87$ in Sample 1 and $\alpha=.83$ in Sample 2). A higher score indicated a stronger basic psychological need at work. Because need strength was treated as an individual difference variable, participants were not asked to refer to their experiences over the past 12 months when responding to this scale.

Van Yperen et al. (2014) conducted a principal component analysis on the items. They concluded that the three psychological needs strengths are empirically distinct concepts. To confirm the validity of this need strength measure, we conducted a confirmatory factor analysis (CFA) in each sample. We specified a one-factor model that included one latent factor representing undifferentiated need strength as well as a three-factor model that included three latent factors, each representing one of the three need strength domains. The standard deviation of each item in both samples exceeded 0.50, indicating adequate variability in the scores (see Stumpf et al. 1983). The CFAs were performed using the R package lavaan (Rosseel 2012). Because of the observed non-normality of the indicator variables, we relied on robust maximum likelihood estimation using the MLM estimator with Satorra-Bentler correction for the test statistic. Latent variables were scaled by fixing the loading of the first item to 1.0. In Sample 1, the three-factor solution $\left(\chi_{\mathrm{SB}}^{2}(51)=106.93, p<.001 ; \mathrm{RMSEA}=.07,90 \% \mathrm{CI}\right.$ $(0.05,0.08)$; CFI $=.96$; SRMR $=.05)$ provided a better fit compared with the one-factor solution $\left(\chi_{\mathrm{SB}}^{2}(54)=833.17\right.$, $p<.001 ;$ RMSEA $=.24,90 \%$ CI $(.23, .26)$; CFI $=.50$;
SRMR = .17). Similarly, in Sample 2, the three-factor solution $\left(\chi_{\mathrm{SB}}^{2}(51)=134.67, p<.001 ; \mathrm{RMSEA}=.08,90 \% \mathrm{CI}\right.$ $(.07, .10)$; CFI $=.94 ;$ SRMR $=.06)$ provided a better fit compared with the one-factor solution $\left(\chi_{\mathrm{SB}}^{2}(54)=650.38\right.$, $p<.001$; RMSEA $=.22,90 \% \mathrm{CI}(.21, .24)$; CFI $=.54$; SRMR $=.16)$. Combined consideration of the fit indices suggested that the fit of the three-factor solution for each sample was at least adequate (Brown 2015; Hu and Bentler 1999).

Work engagement Work engagement was measured using the established nine-item Utrecht Work Engagement scale (UWES-9 scale; Schaufeli et al. 2006). Using a response scale that ranged from (1) never to (7) always (every day), participants responded to items such as "At my job, I felt strong and vigorous" (vigor), "I was enthusiastic about my job" (dedication), and "I felt happy when I was working intensely" (absorption). The reliability estimate was $\alpha=.93$ and $\alpha=.92$ in Sample 1 and Sample 2, respectively. A higher score indicated more frequent experiences of work engagement over the past 12 months.

$O C B$ OCB was measured using an adapted 10 -item version of the Organizational Citizenship Behavior Checklist (OCB-C; Fox et al. 2007) that has been cited and used by Spector et al. (2010). Based on their meta-analytic comparison of self-reported and other-reported OCB, Carpenter et al. (2014) concluded that self-reported OCB may be the preferred method of measuring employees' OCB, and they clearly endorsed its use. We provided a response scale ranging from (1) never to (7) always (every day), which participants used to respond to the items that had been developed based on critical incidents of OCB. Examples of the adapted items include "I volunteered for extra work assignments" and "I lent a compassionate ear when someone had a work problem." The reliability estimate was $\alpha=.89$ and $\alpha=.82$ in Sample 1 and Sample 2, respectively. A higher score indicated more frequent occurrences of OCB over the past 12 months.

\section{Statistical analysis plan}

Regression-based path analysis was performed for each sample to test the hypotheses. We used the PROCESS macro developed for the IBM SPSS Statistics software (Hayes 2013). To obtain the estimates of the predicted indirect relations and the corresponding test results, the statistical models were computed separately for each need domain, while always including the corresponding variables of the other two need domains to control for their effects.

We first selected 'Model 4' in the options menu to compute the point estimates for the unmoderated indirect relations predicted by Hypothesis 1. Each indirect relation is the product of its two constituent relations ( $a$; i.e., the estimated coefficient representing the 'effect' of a need satisfaction 
variable on work engagement, and $b$; i.e., the estimated coefficient representing the 'effect' of work engagement on OCB with the need satisfaction variable controlled for). Accordingly, the coefficient $a b$ refers to the point estimate of the slope of an indirect relation (see Hayes 2013). To test the point estimate of the slope of each indirect relation, 95\% bias-corrected bootstrap confidence intervals based on 10,000 bootstrap samples were computed.

Next, we performed an analysis of the moderation of the indirect relations. We selected 'Model 8' in the options menu, which tests a type of model corresponding to the one depicted in Fig. 1. The need satisfaction and need strength variables were mean-centered, and the corresponding crossproduct terms were computed prior to the analysis (cf., Cohen et al. 2003). The analysis included ordinary least squares (OLS) multiple regression analyses performed successively with work engagement and OCB as the dependent variables, including all need satisfaction and need strength variables as well as the product terms as explanatory variables. The OLS regression analysis including OCB as the dependent variable further included work engagement as an explanatory variable. We used the OLS regression results (see Table 2) to test Hypothesis 2.

When the relation between need satisfaction and work engagement was moderated by need strength, and the relation between work engagement and OCB had a statistically significant slope, then the corresponding indirect relation was assumed to be moderated as well (Hayes 2013; Muller et al. 2005). The output of the PROCESS macro also provides a formal test of moderated mediation (Hayes 2015, p. 9) "based on a quantification of the relationship between the proposed moderator and the size of the indirect effect". This test allows for inferring that "any two conditional indirect effects estimated at different values of the moderator are significantly different from each other" (p. 2) if the corresponding $95 \%$ bootstrap confidence around the point estimate of that quantification excludes zero. This enabled us to test Hypothesis 3. Direct and indirect relations between the need satisfaction variables and OCB were computed at different levels of need strength: namely, average and one $S D$ above and below average (see Tables 3 and 4).

\section{Results}

\section{Correlations and descriptive statistics}

Table 1 presents the means, standard deviations, and correlations among the variables observed in Sample 1 and Sample 2. All correlations of the need satisfaction variables with both OCB and work engagement were positive. Work engagement correlated positively with OCB. This pattern was consistent across both samples. Moreover, except for the correlation between employees' competence satisfaction and need for competence in Sample 2, all need satisfaction variables were consistently and positively correlated with the corresponding need strength variable.

In Sample 1, there were no significant sex differences regarding the variables of research interest, except for female employees reporting a stronger need for competence $(M=5.81, S D=0.99)$ than their male counterparts $(M=5.55, S D=1.08), t(351)=2.37, p=.02$. Analysis of variance revealed no significant mean differences regarding any of the variables of research interest as far as employment status was concerned. As shown in Table 1, employees' age was positively correlated with autonomy satisfaction, competence satisfaction, need for competence, and work engagement, and it was negatively correlated with employees' need

Table 1 Means, standard deviations, and correlations of the variables in Sample 1 and Sample 2

\begin{tabular}{lccccccccccccccc}
\hline Variable & $M_{\text {Sample 1 }}$ & $S D_{\text {Sample 1 }}$ & $M_{\text {Sample 2 }}$ & $S D_{\text {Sample 2 }}$ & 1 & 2 & 3 & 4 & 5 & 6 & 7 & 8 & 9 & 10 \\
\hline 1. Autonomy satisfaction & 4.78 & 1.20 & 5.34 & 1.14 & - & & .42 & .45 & .13 & -.03 & .03 & .62 & .17 & .09 & .12 \\
2. Competence satisfaction & 5.89 & 0.91 & 5.89 & 0.81 & .51 & & .24 & .23 & .05 & -.08 & .39 & .31 & .17 & .11 \\
3. Relatedness satisfaction & 4.81 & 1.45 & 5.13 & 1.13 & .60 & .36 & & -.04 & -.00 & .27 & .40 & .29 & .05 & .13 \\
4. Need for autonomy & 4.90 & 1.30 & 5.42 & 0.82 & .25 & .23 & .13 & - & .45 & .17 & .06 & .22 & .04 & .25 \\
5. Need for competence & 5.71 & 1.03 & 5.28 & 0.74 & .25 & .43 & .18 & .46 & - & .36 & -.04 & .10 & -.20 & .12 \\
6. Need for relatedness & 3.53 & 1.45 & 4.24 & 1.02 & .16 & -.00 & .41 & .27 & .12 & - & -.00 & .14 & -.18 & .04 \\
7. Work engagement & 4.77 & 1.30 & 5.25 & 1.06 & .64 & .48 & .53 & .26 & .34 & .22 & - & .40 & .14 & .23 \\
8. OCB & 4.09 & 1.24 & 4.47 & 0.87 & .22 & .24 & .44 & .27 & .22 & .38 & $.44-$ & .11 .32 \\
9. Age & 38.13 & 11.75 & 44.57 & 10.00 & .12 & .20 & -.03 & .02 & .12 & -.16 & .18 & $-.04-$ & .04 \\
10. Work hours & 37.49 & 10.26 & 37.50 & 8.01 & -.04 & .08 & .12 & .11 & .10 & .05 & .05 & .25 & -.03 & - \\
\hline
\end{tabular}

$N_{\text {Sample 1 }}=353$. Correlations observed in Sample 1 (below the diagonal) higher than .10 and .14 (in absolute values) are significant at the $p=.05$ and $p=.01$ level, respectively. $N_{\text {Sample 2 }}=298$. Correlations observed in Sample 2 (above the diagonal) higher than .11 and .15 (in absolute values) are significant at the $p=.05$ and $p=.01$ level, respectively

${ }^{\mathrm{a} O r g a n i z a t i o n a l ~ c i t i z e n s h i p ~ b e h a v i o r ~}$ 
Table 3 Indirect and direct relations between need satisfaction and organizational citizenship behavior (Sample 1)

\begin{tabular}{|c|c|c|c|}
\hline Need satisfaction & Need strength & Indirect effect & Direct effect \\
\hline \multicolumn{4}{|l|}{ Autonomy } \\
\hline & Low & $a b=0.18, S E_{a b}=0.04,95 \%$ CI $[0.10,0.28]$ & $\mathrm{c}^{\prime}=-0.31, S E \mathrm{c}^{\prime}=0.08,95 \% \mathrm{CI}[-0.47,-0.14]$ \\
\hline & Average & $a b=0.16, S E_{a b}=0.04,95 \%$ CI $[0.10,0.23]$ & $\mathrm{c}^{\prime}=-0.33, S E \mathrm{c}^{\prime}=0.07,95 \% \mathrm{CI}[-0.46,-0.20]$ \\
\hline & High & $a b=0.14, S E_{a b}=0.03,95 \%$ CI $[0.08,0.21]$ & $\mathrm{c}^{\prime}=-0.35, S E \mathrm{c}^{\prime}=0.08,95 \% \mathrm{CI}[-0.51,-0.20]$ \\
\hline \multicolumn{4}{|l|}{ Competence } \\
\hline & Low & $a b=0.08, S E_{a b}=0.03,95 \%$ CI $[0.03,0.15]$ & $\mathrm{c}^{\prime}=0.04, S E \mathrm{c}^{\prime}=0.09,95 \% \mathrm{CI}[-0.13,0.21]$ \\
\hline & Average & $a b=0.07, S E_{a b}=0.03,95 \%$ CI $[0.02,0.13]$ & $\mathrm{c}^{\prime}=0.15, S E \mathrm{c}^{\prime}=0.08,95 \%$ CI $[0.00,0.31]$ \\
\hline & High & $a b=0.05, S E_{a b}=0.04,95 \% \mathrm{CI}[-0.01,0.13]$ & $\mathrm{c}^{\prime}=0.27, S E \mathrm{c}^{\prime}=0.11,95 \%$ CI $[0.06,0.47]$ \\
\hline \multicolumn{4}{|l|}{ Relatedness } \\
\hline & Low & $a b=0.05, S E_{a b}=0.02,95 \%$ CI $[0.01,0.11]$ & $\mathrm{c}^{\prime}=0.30, S E \mathrm{c}^{\prime}=0.06,95 \%$ CI $[0.18,0.41]$ \\
\hline & Average & $a b=0.05, S E_{a b}=0.02,95 \%$ CI $[0.01,0.10]$ & $\mathrm{c}^{\prime}=0.26, S E \mathrm{c}^{\prime}=0.05,95 \%$ CI $[0.16,0.37]$ \\
\hline & High & $a b=0.04, S E_{a b}=0.03,95 \%$ CI $[0.00,0.10]$ & $\mathrm{c}^{\prime}=0.23, S E \mathrm{c}^{\prime}=0.07,95 \%$ CI $[0.09,0.37]$ \\
\hline
\end{tabular}

$N=353$. Low and high need strength refer to values of $1 S D$ below and above the mean of the mean-centered need strength variable, respectively. The confidence intervals pertaining to the indirect relations are $95 \%$ bias-corrected bootstrap confidence intervals

was relatively high (one $S D$ above the mean), $b_{\mathrm{s}}=0.27$, $t(342)=2.52, p=.01$. However, this was not the case for employees whose need for competence was relatively low (one $S D$ below the mean), $b_{\mathrm{s}}=0.04, t(342)=0.50, p=.62$.

In Sample 2, the interaction between relatedness satisfaction and the need for relatedness was predictive of work engagement. Simple slopes analysis revealed that the relation between relatedness satisfaction and work engagement was statistically significant for employees whose need for relatedness was relatively high (one $S D$ above the mean), $b_{\mathrm{s}}=0.25, t(288)=3.92, p<.001$. However, this was not the case for employees whose need for relatedness was relatively low (one $S D$ below the mean), $b_{\mathrm{s}}=0.05, t(288)=0.86$, $p=.39$. The remaining interaction effects between need satisfaction and need strength were not statistically significant for any of the outcome variables. Except for autonomy satisfaction, which was consistently predictive of a negative rather than a positive direction of $\mathrm{OCB}$, the remaining relations between each need satisfaction variable and the two outcomes matched our expectations. ${ }^{4}$

Hypothesis 3 Our third hypothesis proposed that positive indirect relations between work-related satisfaction of each basic psychological need and OCB through work engagement strengthened as employees' corresponding work-specific need strength increased. Tables 3 and 4, respectively, show the indirect relations obtained for Sample 1 and

\footnotetext{
4 The negative regression coefficient of autonomy satisfaction in each sample may be an example of negative suppression. According to Kline (2016), negative suppression is present if the explanatory variables of concern (here: autonomy satisfaction and work engagement) are positively correlated with the criterion variable (here: OCB) and with each other, but then one of these explanatory variables has a negative regression coefficient (here: autonomy satisfaction).
}

Sample 2 at the different values of need strength. In accordance with the results of Hypothesis 2, a moderated indirect relation was found for the relatedness need domain in Sample 2. The results confirmed that there was a significant indirect relation between relatedness satisfaction and OCB through work engagement for employees whose need for relatedness was relatively high (one $S D$ above the mean) as well as average. However, this was not the case for employees whose need for relatedness was relatively low (one $S D$ below the mean). The results regarding Hypothesis 2 did not warrant the inference that the remaining indirect relations were enhanced when need strength increased. Indeed, the formal test of moderated mediation (Hayes 2015) confirmed that no further indirect relation was moderated by need strength. In Sample 1, the point estimate of the index of moderated mediation and the corresponding $95 \%$ bootstrap confidence interval (in brackets) were $-0.02,[-0.05$, $0.01],-0.02,[-0.05,0.02]$, and 0.00, [-0.02, 0.01], for the autonomy, competence, and relatedness need domains, respectively. In Sample 2, the point estimate of the index of moderated mediation and the corresponding $95 \%$ bootstrap confidence interval (in brackets) were 0.01, [ -0.03 , 0.07], - 0.03, [- 0.09, 0.03], and 0.03, [0.004, 0.078] for the autonomy, competence, and relatedness need domains, respectively.

\section{Discussion}

An important theoretical debate in the literature on psychological needs concerns the potential moderating effect of need strength on relations between basic psychological need satisfaction (BPNS; Deci and Ryan 2000) and outcomes. It has focused on the question of whether positive outcomes 
Table 4 Indirect and direct relations between need satisfaction and organizational citizenship behavior (Sample 2)

\begin{tabular}{|c|c|c|c|}
\hline Need satisfaction & Need strength & Indirect effect & Direct effect \\
\hline \multicolumn{4}{|l|}{ Autonomy } \\
\hline & Low & $a b=0.15, S E_{a b}=0.04,95 \%$ CI $[0.08,0.24]$ & $\mathrm{c}^{\prime}=-0.26, S E \mathrm{c}^{\prime}=0.07,95 \% \mathrm{CI}[-0.40,-0.12]$ \\
\hline & Average & $a b=0.16, S E_{a b}=0.03,95 \%$ CI $[0.10,0.24]$ & $\mathrm{c}^{\prime}=-0.23, S E \mathrm{c}^{\prime}=0.05,95 \% \mathrm{CI}[-0.33,-0.12]$ \\
\hline & High & $a b=0.17, S E_{a b}=0.04,95 \%$ CI $[0.12,0.26]$ & $\mathrm{c}^{\prime}=-0.20, S E \mathrm{c}^{\prime}=0.06,95 \% \mathrm{CI}[-0.32,-0.07]$ \\
\hline \multicolumn{4}{|l|}{ Competence } \\
\hline & Low & $a b=0.08, S E_{a b}=0.04,95 \%$ CI $[0.02,0.16]$ & $\mathrm{c}^{\prime}=0.25, S E \mathrm{c}^{\prime}=0.08,95 \% \mathrm{CI}[0.08,0.42]$ \\
\hline & Average & $a b=0.06, S E_{a b}=0.03,95 \%$ CI $[0.01,0.13]$ & $\mathrm{c}^{\prime}=0.21, S E \mathrm{c}^{\prime}=0.06,95 \% \mathrm{CI}[0.08,0.33]$ \\
\hline & High & $a b=0.04, S E_{a b}=0.04,95 \% \mathrm{CI}[-0.03,0.12]$ & $\mathrm{c}^{\prime}=0.17, S E \mathrm{c}^{\prime}=0.08,95 \%$ CI $[0.00,0.33]$ \\
\hline \multicolumn{4}{|l|}{ Relatedness } \\
\hline & Low & $a b=0.02, S E_{a b}=0.02,95 \%$ CI $[-0.03,0.06]$ & $\mathrm{c}^{\prime}=0.18, S E \mathrm{c}^{\prime}=0.06,95 \%$ CI $[0.08,0.29]$ \\
\hline & Average & $a b=0.05, S E_{a b}=0.02,95 \%$ CI $[0.02,0.10]$ & $\mathrm{c}^{\prime}=0.15, S E \mathrm{c}^{\prime}=0.05,95 \%$ CI $[0.06,0.24]$ \\
\hline & High & $a b=0.09, S E_{a b}=0.03,95 \%$ CI $[0.04,0.15]$ & $\mathrm{c}^{\prime}=0.11, S E \mathrm{c}^{\prime}=0.06,95 \% \mathrm{CI}[-0.01,0.23]$ \\
\hline
\end{tabular}

$N=298$. Low and high need strength refer to values of $1 S D$ below and above the mean of the mean-centered need strength variable, respectively. The confidence intervals pertaining to the indirect relations are $95 \%$ bias-corrected bootstrap confidence intervals

of BPNS are more pronounced the higher individuals' need strength (i.e., the matching hypothesis; Schüler et al. 2013). Previous studies addressing this question yielded inconsistent findings. In the current research, we examined whether employees' work-specific explicit autonomy, competence, and relatedness need strength enhanced indirect and direct relations between corresponding work-related need satisfaction and organizational citizenship behavior (OCB).

Across two independent samples of employees and across the three basic need domains, our results consistently confirmed the hypothesized indirect relations between BPNS and OCB through work engagement. However, we found only minor evidence for a moderating role of need strength. That is, each sample evidenced support for only one interactive effect between need satisfaction and need strength, and these effects were inconsistent across outcome variables and need domains. Specifically, employees' work-specific explicit need for competence moderated the direct relation between competence satisfaction and OCB in Sample 1. In Sample 2, employees' work-specific explicit need for relatedness moderated the direct relation between relatedness satisfaction and work engagement. In keeping with these results, only the indirect relation between relatedness satisfaction and OCB through work engagement in Sample 2 was moderated by employees' need for relatedness.

Further analysis of the observed interaction effects revealed that the relations did not exist for employees who had a comparatively weak corresponding psychological need at work (cf., Schüler et al. 2016). This finding is neither in line with the postulate of the matching hypothesis (Schüler et al. 2013), nor with the more liberal universalistic perspective on the benefits of BPNS (Soenens et al. 2015; see also Van Assche et al. 2018). Taken together, our main findings largely did not support our hypotheses that need strength moderates the relations between BPNS and our outcome variables (i.e., work engagement and OCB). That is, our findings reconfirm and extend Chen et al.'s (2015) findings to (a) work-specific outcomes; (b) a (self-reported) behavioral outcome variable (OCB); (c) a domain-specific population (employees); and (d) domain-specific measurement of need strength and need satisfaction.

In the present research, we followed Schüler et al.'s (2013) recommendation to rely on domain-specific outcome variables when testing the moderating role of need strength. In several studies, it was found that individuals' need strength enhanced the effects of need satisfaction when the outcome variable was domain-specific (e.g., Hofer and Busch 2011; Schüler and Brandstätter 2013). Nevertheless, there was only minor evidence of a moderation effect for our domain-specific outcome variables. This may be explained by our explicit measure of need strength. We relied on this measure because it was developed and successfully used for assessing individuals' need strength in the work domain (Van Yperen et al. 2014, 2016). However, explicit measures of need strength may be less sensitive than their implicit counterparts in revealing interaction effects (Van Assche et al. 2018). This is supported by the finding of previous studies relying on explicit need strength that the moderation effect was rather small (Flunger et al. 2013; Katz et al. 2010).

Additional findings of our study suggest that, albeit unaffected by different levels of explicit need strength, feeling autonomous, competent, or connected to colleagues in the workplace is associated with a heightened likelihood of employees' engagement in their jobs. In turn, employees' work engagement is positively related to their self-reported behaviors such as volunteering for extra tasks, suggesting improvements, and helping coworkers. Our consistent 
finding pertaining to the indirect relations adds to previous research that did not consider intermediate variables in the relations between BPNS in the workplace and OCB (e.g., Roche and Haar 2013). It resembles the finding of Salanova and Schaufeli (2008), who showed that work engagement accounted for an indirect relation between job-related resources (job control, feedback, and task variety) and proactive work behavior. Thus, there is cumulative evidence that relations between resources at work (either psychological or job-related) and constructive voluntary job performance may be linked through work engagement. Moreover, the consistent and positive main effect of employees' work-related need for autonomy on OCB, which we observed in the current study, may suggest that particularly individual differences in work-related autonomy need strength contribute to explanations of variance in work-related outcomes (cf., Van Yperen et al. 2014, 2016).

Another aspect of our results is noteworthy. In both samples, approximately half of the variance in work engagement and one-third of the variance in OCB were explained by our explanatory variables. This finding validates the inference that the SDT approach to needs, when applied to the workplace, has a high degree of value for predicting mental vigor, job-related dedication, and task absorption. In turn, psychological need satisfaction and work engagement, in combination, seem to have considerable value for predicting employees' self-reported OCB.

Our findings dovetail with the assertions of the basic SDT model for the workplace (Deci et al. 2017), which regards BPNS as an antecedent of work performance, among other things. The present findings endorse core SDT assertions, as they largely underscore the importance of BPNS (Deci and Ryan 2000). Hence, rather than ensuring fit (cf., KristofBrown et al. 2005) between need satisfaction and need strength, we recommend focusing on providing on-the-job opportunities for enabling the satisfaction of employees' work-specific needs for autonomy, competence, and relatedness to increase the likelihood of constructive voluntary job performance and work engagement in the workforce. Optimizing work design (Parker 2014) could ensure, for instance, that job tasks are somewhat challenging but not overwhelmingly so. Moreover, employees should be able to decide for themselves how to execute and develop their job tasks, and they should have opportunities to bond with their colleagues through time spent together and through working together in compatible teams to achieve common goals.

\section{Strengths and limitations}

One of the strengths of the current study is our use of two independent samples that yielded convergent findings among employees from the United States and the Netherlands. This sampling method strengthens the reliability and generalizability of our findings. A second strength of the current study is that, unlike most previous studies of the moderating role of need strength, we considered each basic psychological need domain. We also considered each need separately rather than using an all-encompassing construct representing BPNS. Our findings showed that the satisfaction of each separate psychological need could independently explain parts of the variance present in each outcome variable (cf., Van den Broeck et al. 2016).

One limitation of our study is common method bias; that is, the exclusive reliance on self-report data (Podsakoff et al. 2003). However, valid indices of BPNS and work engagement can be obtained only through self-report. Furthermore, although future research may also include other source indices of employees' behavior, it is noteworthy that measuring self-reported OCB has been encouraged strongly based on meta-analytic findings (Carpenter et al. 2014). Another limitation is the cross-sectional design of our study, particularly because our conceptual model implies a causal sequence. Thus, we can only make claims about indirect relations (e.g., Kline 2016) between the variables of our research model, which was theoretically grounded in the assertions of SDT. This strong theoretical foundation serves to counter the absence of time precedence in the measurements (Hayes 2013). It is important to note, however, that BPNS is most likely to be associated reciprocally with OCB. For example, Penner et al. (1997) suggested that employees may exhibit OCB to serve their needs or motives (e.g., to serve an altruistic motive of helping others). Several types of OCB, such as helping coworkers or completing extra work assignments, could be conducive to competence satisfaction. In a similar vein, OCB that entails helping others may ultimately contribute to strengthening feelings of being connected to coworkers. Moreover, it is conceivable that OCB that is performed proactively can contribute to satisfying employees' need for autonomy.

\section{Future research and conclusion}

To disentangle the inconsistency in findings regarding the moderating role of need strength, future research may follow an all-encompassing approach by including all three need domains as well as domain-specific and more general need satisfaction, need strength (explicit and implicit), and outcome variables (see also Ryan et al. 2019). Another option for future research is to explore the moderating effect of need strength on the relation between basic psychological need frustration and destructive voluntary job performance (see Van den Broeck et al. 2014). This question would be intriguing to address considering Flunger et al.'s (2013) conclusion that the evidence for the moderation effect of need strength on the relation between need 
frustration and outcomes was more convincing than evidence for the moderating effect of need strength on the relation between need satisfaction and outcomes. Another avenue for future studies is to provide cumulative evidence for our findings pertaining to the indirect relations between BPNS and OCB through engagement. For example, the experimental-causal-chain approach to mediation may be the best methodology for testing the implied causality (Spencer et al. 2005). This approach would require two experiments to be conducted. The first would entail a manipulation of need satisfaction (e.g., Sheldon and Filak 2008) and the second would focus on manipulating engagement. One way to operationalize OCB is to follow a procedure employed by Twenge et al. (2007) within an experimental setting that entails extending assistance to another person by volunteering for additional tasks.

In conclusion, the satisfaction of individuals' psychological needs for autonomy, competence, and relatedness has been identified as essential for sustaining optimal psychological functioning and motivation (Deci and Ryan 2000; Ryan and Deci 2000; Vansteenkiste and Ryan 2013). In line with this central tenet of SDT, our findings highlight the relevance of employees' basic psychological need satisfaction rather than fit between high need satisfaction and high need strength in the workplace.

\section{Compliance with ethical standards}

Ethical approval All procedures performed in studies involving human participants were in accordance with the ethical standards of the institutional and/or national research committee and with the 1964 Helsinki declaration and its later amendments or comparable ethical standards. This article does not contain any studies with animals performed by any of the authors.

Informed consent Informed consent was obtained from all individual participants included in the study.

Open Access This article is distributed under the terms of the Creative Commons Attribution 4.0 International License (http://creativeco mmons.org/licenses/by/4.0/), which permits unrestricted use, distribution, and reproduction in any medium, provided you give appropriate credit to the original author(s) and the source, provide a link to the Creative Commons license, and indicate if changes were made.

\section{References}

Bakker, A. B., \& Demerouti, E. (2008). Towards a model of work engagement. Career Development International, 13, 209-223. https://doi.org/10.1108/13620430810870476.

Bakker, A. B., Demerouti, E., \& Ten Brummelhuis, L. L. (2012). Work engagement, performance, and active learning: The role of conscientiousness. Journal of Vocational Behavior, 80, 555-564. https ://doi.org/10.1016/j.jvb.2011.08.008.
Bakker, A. B., Schaufeli, W. B., Leiter, M. P., \& Taris, T. W. (2008). Work engagement: An emerging concept in occupational health psychology. Work \& Stress, 22, 187-200. https://doi. org/10.1080/02678370802393649.

Baumeister, R. F., \& Leary, M. R. (1995). The need to belong: Desire for interpersonal attachments as a fundamental human motivation. Psychological Bulletin, 117, 497-529. https://doi. org/10.1037/0033-2909.117.3.497.

Becker, T. E., Atinc, G., Breaugh, J. A., Carlson, K. D., Edwards, J. R., \& Spector, P. E. (2016). Statistical control in correlational studies: 10 essential recommendations for organizational researchers. Journal of Organizational Behavior, 37, 157-167. https://doi.org/10.1002/job.2053.

Brown, T. A. (2015). Confirmatory factor analysis for applied research. New York, NY: Guilford Press.

Buhrmester, M., Kwang, T., \& Gosling, S. D. (2011). Amazon's Mechanical Turk: A new source of inexpensive, yet high-quality, data? Perspectives on Psychological Science, 6, 3-5. https ://doi.org/10.1177/1745691610393980.

Carpenter, N. C., Berry, C. M., \& Houston, L. (2014). A meta-analytic comparison of self-reported and other-reported organizational citizenship behavior. Journal of Organizational Behavior, 35, 547-574. https://doi.org/10.1002/job.1909.

Chen, B., Vansteenkiste, M., Beyers, W., Boone, L., Deci, E. L., Van der Kaap-Deeder, J., et al. (2015). Basic psychological need satisfaction, need frustration, and need strength across four cultures. Motivation and Emotion, 39, 216-236. https:// doi.org/10.1007/s11031-014-9450-1.

Cheung, J. H., Burns, D. K., Sinclair, R. R., \& Sliter, M. (2017). Amazon Mechanical Turk in organizational psychology: An evaluation and practical recommendations. Journal of Business and Psychology, 32, 347-361. https://doi.org/10.1007/ s10869-016-9458-5.

Christian, M. S., Garza, A. S., \& Slaughter, J. E. (2011). Work engagement: A quantitative review and test of its relations with task and contextual performance. Personnel Psychology, 64, 89-136. https://doi.org/10.1111/j.1744-6570.2010.01203.x.

Cohen, J., Cohen, P., West, S. G., \& Aiken, L. S. (2003). Applied multiple regression/correlation analysis for the behavioral sciences (3rd ed.). Mahwah, NJ: Lawrence Erlbaum Associates Publishers.

Dalal, R. S., Baysinger, M., Brummel, B. J., \& LeBreton, J. M. (2012). The relative importance of employee engagement, other job attitudes, and trait affect as predictors of job performance. Journal of Applied Social Psychology, 42, 295-325. https://doi.org/10.11 11/j.1559-1816.2012.01017.x.

Deci, E. L., Olafsen, A. H., \& Ryan, R. M. (2017). Self-determination theory in work organizations: The state of a science. Annual Review of Organizational Psychology and Organizational Behavior, 4, 19-43. https://doi.org/10.1146/annurev-orgpsych-03251 6-113108.

Deci, E. L., \& Ryan, R. M. (2000). The "what" and "why" of goal pursuits: Human needs and the self-determination of behavior. Psychological Inquiry, 11, 227-268. https://doi.org/10.1207/ S15327965PLI1104_01.

Fernet, C., Austin, S., Trépanier, S.-G., \& Dussault, M. (2013). How do job characteristics contribute to burnout? Exploring the distinct mediating roles of perceived autonomy, competence, and relatedness. European Journal of Work and Organizational Psychology, 22, 123-137. https://doi.org/10.1080/1359432X.2011.632161.

Flunger, B., Pretsch, J., Schmitt, M., \& Ludwig, P. (2013). The role of explicit need strength for emotions during learning. Learning and Individual Differences, 23, 241-248. https://doi.org/10.1016/j. lindif.2012.10.001.

Fox, J., Spector, P. E., Bruursema, K., Kessler, S., \& Goh, A. (2007). Necessity is the mother of behavior: Organizational constraints, 
$C W B$ and $O C B$. Paper presented at the meeting of the Academy of Management, Philadelphia, PA.

Fox, S., Spector, P. E., Goh, A., Bruursema, K., \& Kessler, S. R. (2012). The deviant citizen: Measuring potential positive relations between counterproductive work behaviour and organizational citizenship behaviour. Journal of Occupational and Organizational Psychology, 85, 199-220. https://doi.org/10.111 1/j.2044-8325.2011.02032.x.

Gagné, M., \& Deci, E. L. (2005). Self-determination theory and work motivation. Journal of Organizational Behavior, 26, 331-362. https://doi.org/10.1002/job.322.

George, J. M., \& Brief, A. P. (1992). Feeling good-doing good: A conceptual analysis of the mood at work-organizational spontaneity relationship. Psychological Bulletin, 112, 310-329. https ://doi.org/10.1037/0033-2909.112.2.310.

Harris, C., Daniels, K., \& Briner, R. B. (2003). A daily diary study of goals and affective well-being at work. Journal of Occupational and Organizational Psychology, 76, 401-410. https://doi. org/10.1348/096317903769647256.

Hayes, A. F. (2013). Introduction to mediation, moderation, and conditional process analysis: A regression-based approach. New York: Guilford Press.

Hayes, A. F. (2015). An index and test of linear moderated mediation. Multivariate Behavioral Research, 50, 1-22. https://doi. org/10.1080/00273171.2014.962683.

Hodge, K., Lonsdale, C., \& Jackson, S. A. (2009). Athlete engagement in elite sport: An exploratory investigation of antecedents and consequences. The Sport Psychologist, 23, 186-202. https ://doi.org/10.1123/tsp.23.2.186.

Hofer, J., \& Busch, H. (2011). Satisfying one's needs for competence and relatedness: Consequent domain-specific wellbeing depends on strength of implicit motives. Personality and Social Psychology Bulletin, 37, 1147-1158. https://doi. org/10.1177/0146167211408329.

Hu, L.-T., \& Bentler, P. M. (1999). Cutoff criteria for fit indexes in covariance structure analysis: Conventional criteria versus new alternatives. Structural Equation Modeling, 6, 1-55. https://doi. org/10.1080/10705519909540118.

Katz, I., Kaplan, A., \& Gueta, G. (2010). Students' needs, teachers' support, and motivation for doing homework: A cross-sectional study. Journal of Experimental Education, 78, 246-267. https ://doi.org/10.1080/00220970903292868.

Keith, M. G., Tay, L., \& Harms, P. D. (2017). Systems perspective of Amazon Mechanical Turk for organizational research: Review and recommendations. Frontiers in Psychology, 8, 1-19. https ://doi.org/10.3389/fpsyg.2017.01359.

Kline, R. B. (2016). Principles and practice of structural equation modeling (4th ed.). New York: Guilford Press.

Korthagen, F. A. J., \& Evelein, F. G. (2016). Relations between student teachers' basic needs fulfillment and their teaching behavior. Teaching and Teacher Education, 60, 234-244. https://doi. org/10.1016/j.tate.2016.08.021.

Kristof-Brown, A. L., Zimmerman, R. D., \& Johnson, E. C. (2005). Consequences of individuals' fit at work: A meta-analysis of person-job, person-organization, person-group, and personsupervisor fit. Personnel Psychology, 58, 285-342. https://doi. org/10.1111/j.1744-6570.2005.00672.x.

Landers, R. N., \& Behrend, T. S. (2015). An inconvenient truth: Arbitrary distinctions between organizational, Mechanical Turk, and other convenience samples. Industrial and Organizational Psychology, 8, 142-164. https://doi.org/10.1017/ iop. 2015.13 .

Mason, W., \& Suri, S. (2012). Conducting behavioral research on Amazon's Mechanical Turk. Behavior Research Methods, 44, 1-23. https://doi.org/10.3758/s13428-011-0124-6.
May, D. R., Gilson, R. L., \& Harter, L. M. (2004). The psychological conditions of meaningfulness, safety and availability and the engagement of the human spirit at work. Journal of Occupational \& Organizational Psychology, 77, 11-37. https://doi. org/10.1348/096317904322915892.

McClelland, D. C. (1985). Human motivation. New York: Cambridge University Press.

Meade, A. W., \& Craig, S. B. (2012). Identifying careless responses in survey data. Psychological Methods, 17, 437-455. https:// doi.org/10.1037/a0028085.

Muller, D., Judd, C. M., \& Yzerbyt, V. Y. (2005). When mediation is moderated and moderation is mediated. Journal of Personality and Social Psychology, 89, 852-863. https://doi. org/10.1037/0022-3514.89.6.852.

Organ, D. W. (1997). Organizational citizenship behavior: It's construct clean-up time. Human Performance, 10, 85-97. https:// doi.org/10.1207/s15327043hup1002_2.

Organ, D. W., Podsakoff, P. M., \& MacKenzie, S. B. (2006). Organizational citizenship behavior: Its nature, antecedents, and consequences. Thousand Oaks: Sage.

Paolacci, G., \& Chandler, J. (2014). Inside the Turk: Understanding Mechanical Turk as a participant pool. Current Directions in Psychological Science, 23, 184-188. https://doi. org/10.1177/0963721414531598.

Parker, S. K. (2014). Beyond motivation: Job and work design for development, health, ambidexterity, and more. Annual Review of Psychology, 65, 661-691. https://doi.org/10.1146/annurevpsych-010213-115208.

Penner, L. A., Midili, A. R., \& Kegelmeyer, J. (1997). Beyond job attitudes: A personality and social psychology perspective on the causes of organizational citizenship behavior. Human Performance, 10, 111-131. https://doi.org/10.1207/s15327043h up1002_4.

Podsakoff, P. M., MacKenzie, S. B., Lee, J.-Y., \& Podsakoff, N. P. (2003). Common method biases in behavioral research: A critical review of the literature and recommended remedies. Journal of Applied Psychology, 88, 879-903. https://doi. org/10.1037/0021-9010.88.5.879.

Podsakoff, N. P., Whiting, S. W., Podsakoff, P. M., \& Blume, B. D. (2009). Individual- and organizational-level consequences of organizational citizenship behaviors: A meta-analysis. Journal of Applied Psychology, 94, 122-141. https://doi.org/10.1037/ a0013079.

Roche, M., \& Haar, J. M. (2013). A metamodel approach towards self-determination theory: A study of New Zealand managers' organisational citizenship behaviours. The International Journal of Human Resource Management, 24, 3397-3417. https:// doi.org/10.1080/09585192.2013.770779.

Rosseel, Y. (2012). lavaan: An R package for structural equation modeling. Journal of Statistical Software, 48, 1-36. https://doi. org/10.18637/jss.v048.i02.

Rotundo, M., \& Sackett, P. R. (2002). The relative importance of task, citizenship, and counterproductive performance to global ratings of job performance: A policy-capturing approach. Journal of Applied Psychology, 87, 66-80. https://doi. org/10.1037/0021-9010.87.1.66.

Ryan, R. M., \& Deci, E. L. (2000). Self-determination theory and the facilitation of intrinsic motivation, social development, and well-being. American Psychologist, 55, 68-78. https://doi. org/10.1037//0003-066X.55.1.68.

Ryan, R. M., Soenens, B., \& Vansteenkiste, M. (2019). Reflections on self-determination theory as an organizing framework for personality psychology: Interfaces, integrations, issues, and unfinished business. Journal of Personality, 87, 115-145. https ://doi.org/10.1111/jopy.12440. 
Salanova, M., \& Schaufeli, W. B. (2008). A cross-national study of work engagement as a mediator between job resources and proactive behaviour. The International Journal of Human Resource Management, 19, 116-131. https://doi.org/10.1080/0958519070 1763982.

Schaufeli, W. B., Bakker, A. B., \& Salanova, M. (2006). The measurement of work engagement with a short questionnaire: A cross-national study. Educational and Psychological Measurement, 66, 701-716. https://doi.org/10.1177/0013164405282471.

Schaufeli, W. B., Salanova, M., González-Romá, V., \& Bakker, A. B. (2002). The measurement of engagement and burnout: A two sample confirmatory factor analytic approach. Journal of Happiness Studies, 3, 71-92. https://doi.org/10.1023/A:1015630930326.

Schüler, J., Baumann, N., Chasiotis, A., Bender, M., \& Baum, I. (2019). Implicit motives and basic psychological needs. Journal of Personality, 87, 37-55. https://doi.org/10.1111/jopy.12431.

Schüler, J., \& Brandstätter, V. (2013). How basic need satisfaction and dispositional motives interact in predicting flow experience in sport. Journal of Applied Social Psychology, 43, 687-705. https ://doi.org/10.1111/j.1559-1816.2013.01045.x.

Schüler, J., Brandstätter, V., \& Sheldon, K. M. (2013). Do implicit motives and basic psychological needs interact to predict wellbeing and flow? Testing a universal hypothesis and a matching hypothesis. Motivation and Emotion, 37, 480-495. https://doi. org/10.1007/s11031-012-9317-2.

Schüler, J., Sheldon, K. M., \& Fröhlich, S. M. (2010). Implicit need for achievement moderates the relationship between competence need satisfaction and subsequent motivation. Journal of Research in Personality, 44, 1-12. https://doi.org/10.1016/j.jrp.2009.09.002.

Schüler, J., Sheldon, K. M., Prentice, M., \& Halusic, M. (2016). Do some people need autonomy more than others? Implicit dispositions toward autonomy moderate the effects of felt autonomy on well-being. Journal of Personality, 84, 5-20. https://doi. org/10.1111/jopy. 12133 .

Sheldon, K. M., \& Filak, V. (2008). Manipulating autonomy, competence, and relatedness support in a game-learning context: New evidence that all three needs matter. British Journal of Social Psychology, 47, 267-283. https://doi.org/10.1348/014466607X 238797.

Sheldon, K. M., \& Schüler, J. (2011). Wanting, having, and needing: Integrating motive disposition theory and self-determination theory. Journal of Personality and Social Psychology, 101, 11061123. https://doi.org/10.1037/a0024952.

Soenens, B., Vansteenkiste, M., \& Van Petegem, S. (2015). Let us not throw out the baby with the bathwater: Applying the principle of universalism without uniformity to autonomy-supportive and controlling parenting. Child Development Perspectives, 9, 44-49. https://doi.org/10.1111/cdep.12103.

Spector, P. E., Bauer, J. A., \& Fox, S. (2010). Measurement artifacts in the assessment of counterproductive work behavior and organizational citizenship behavior: Do we know what we think we know? Journal of Applied Psychology, 95, 781-790. https://doi. org/10.1037/a0019477.

Spector, P. E., \& Fox, S. (2002). An emotion-centered model of voluntary work behavior: Some parallels between counterproductive work behavior and organizational citizenship behavior. Human Resource Management Review, 12, 269-292. https://doi. org/10.1016/S1053-4822(02)00049-9.

Spencer, S. J., Zanna, M. P., \& Fong, G. T. (2005). Establishing a causal chain: Why experiments are often more effective than mediational analyses in examining psychological processes. Journal of Personality and Social Psychology, 89, 845-851. https:// doi.org/10.1037/0022-3514.89.6.845.

Stumpf, S. A., Colarelli, S. M., \& Hartman, K. (1983). Development of the career exploration survey (CES). Journal of Vocational Behavior, 22, 191-226. https://doi.org/10.1016/0001-8791(83)90028-3.
Trépanier, S.-G., Fernet, C., \& Austin, S. (2013). Workplace bullying and psychological health at work: The mediating role of satisfaction of needs for autonomy, competence and relatedness. Work \& Stress, 27, 123-140. https://doi.org/10.1080/02678 373.2013.782158.

Twenge, J. M., Baumeister, R. F., DeWall, C. N., Ciarocco, N. J., \& Bartels, J. M. (2007). Social exclusion decreases prosocial behavior. Journal of Personality and Social Psychology, 92, 56-66. https://doi.org/10.1037/0022-3514.92.1.56.

Van Assche, J., van der Kaap-Deeder, J., Audenaert, E., De Schryver, M., \& Vansteenkiste, M. (2018). Are the benefits of autonomy satisfaction and the costs of autonomy frustration dependent on individuals' autonomy strength? Journal of Personality, 86, 1017-1036. https://doi.org/10.1111/jopy.12372.

Van den Broeck, A., Ferris, D. L., Chang, C.-H., \& Rosen, C. C. (2016). A review of self-determination theory's basic psychological needs at work. Journal of Management, 42, 1195-1229. https ://doi.org/10.1177/0149206316632058.

Van den Broeck, A., Vansteenkiste, M., De Witte, H., Soenens, B., \& Lens, W. (2010). Capturing autonomy, competence, and relatedness at work: Construction and initial validation of the work-related basic need satisfaction scale. Journal of Occupational and Organizational Psychology, 83, 981-1002. https://doi. org/10.1348/096317909X481382.

Van Wijhe, C., Peeters, M., Schaufeli, W. B., \& Van den Hout, M. (2011). Understanding workaholism and work engagement: The role of mood and stop rules. Career Development International, 16, 254-270. https://doi.org/10.1108/13620431111140156.

Van Yperen, N. W., Rietzschel, E. F., \& De Jonge, K. M. M. (2014). Blended working: For whom it may (not) work. PLoS ONE, 9, 1-8. https://doi.org/10.1371/journal.pone.0102921.

Van Yperen, N. W., Wörtler, B., \& De Jonge, K. M. M. (2016). Workers' intrinsic work motivation when job demands are high: The role of need for autonomy and perceived opportunity for blended working. Computers in Human Behavior, 60, 179-184. https://doi. org/10.1016/j.chb.2016.02.068.

Vansteenkiste, M., Neyrinck, B., Niemiec, C. P., Soenens, B., De Witte, H., \& Van den Broeck, A. (2007). On the relations among work value orientations, psychological need satisfaction and job outcomes: A self-determination theory approach. Journal of Occupational and Organizational Psychology, 80, 251-277. https://doi. org/10.1348/096317906X111024.

Vansteenkiste, M., Niemiec, C. P., \& Soenens, B. (2010). The development of the five mini-theories of self-determination theory: A historical overview, emerging trends and future directions. In T. Urdan \& S. Karabenick (Eds.), The decade ahead: Theoretical perspectives on motivation and achievement (Vol. 16, pp. 105166). Bingley: Emerald Group Publishing Limited.

Vansteenkiste, M., \& Ryan, R. M. (2013). On psychological growth and vulnerability: Basic psychological need satisfaction and need frustration as a unifying principle. Journal of Psychotherapy Integration, 23, 263-280. https://doi.org/10.1037/a0032359.

Xanthopoulou, D., Bakker, A. B., Demerouti, E., \& Schaufeli, W. B. (2007). The role of personal resources in the job demandsresources model. International Journal of Stress Management, 14, 121-141. https://doi.org/10.1037/1072-5245.14.2.121.

Yen, H. R., \& Niehoff, B. P. (2004). Organizational citizenship behaviors and organizational effectiveness: Examining relationships in Taiwanese banks. Journal of Applied Social Psychology, 34, 1617-1637. https://doi.org/10.1111/j.1559-1816.2004.tb02790.x.

Publisher's Note Springer Nature remains neutral with regard to jurisdictional claims in published maps and institutional affiliations. 